\title{
Evidence of photoinduced lipid hydroperoxidation in Langmuir monolayers containing Eosin $\mathrm{Y}$
}

\author{
Lucas S.A. Pereira ${ }^{\mathrm{a}}$, Sabrina A. Camacho ${ }^{\mathrm{a}}$, Antonio A. Malfatti-Gasperini ${ }^{\mathrm{b}}$, Karen Jochelavicius ${ }^{\mathrm{c}}$, \\ Thatyane M. Nobre ${ }^{c}$, Osvaldo N. Oliveira Jr. ${ }^{c}$, Pedro H.B. Aoki ${ }^{\mathrm{a}, *}$ \\ ${ }^{a}$ School of Sciences, Humanities and Languages, São Paulo State University (UNESP), Assis, SP, 19806-900, Brazil \\ ${ }^{\mathrm{b}}$ Brazilian Synchrotron Light Laboratory-LNLS, CNPEM, Rua Giuseppe Maximo Scolfaro, 10000, Campinas, SP 13083-070, Brazil \\ ${ }^{c}$ IFSC, Sao Carlos Institute of Physics, University of São Paulo (USP), Sao Carlos, SP, 13566-590, Brazil
}

\section{A R T I C L E I N F O}

\section{Keywords:}

Langmuir monolayers

Cell membrane models

Photosensitizers

Eosin Y

PM-IRRAS

GIXOS

Hydroperoxidation

\begin{abstract}
A B S T R A C T
Photodynamic therapy (PDT) efficiency depends on many factors including the incorporation of the photosensitizer (PS) in cell membranes and possible lipid hydroperoxidation. In this study, we show that hydroperoxidation may be photoinduced when eosin $\mathrm{Y}$ is incorporated into Langmuir monolayers that serve as cell membrane models. This occurs for Langmuir monolayers of 1,2-dioleoyl-sn-glycero-3-phosphocholine (DOPC) and 1-palmitoyl-2-oleoyl-sn-glycero-3-phosphocholine (POPC), which have unsaturation in their hydrophobic chains. In contrast, light irradiation had no effect on monolayers of saturated 1,2-dipalmitoyl-sn-glycero-3phosphocholine (DPPC). Evidence of hydroperoxidation was obtained from the area increase in eosin-containing DOPC and POPC monolayers upon irradiation, which was accompanied by a decrease in monolayer thickness according to grazing incidence X-ray off-specular scattering (GIXOS) data. Furthermore, the changes in polarization-modulated infrared reflection absorption spectroscopy (PM-IRRAS) induced by irradiation were consistent with hydroperoxide migration toward the lipid hydrophilic heads.. In summary, this combination of experimental methods allowed us to determine the effects of eosin Y interaction with cell membrane models under irradiation, which may be associated with the underlying mechanisms of eosin $\mathrm{Y}$ as photosensitizer in PDT.
\end{abstract}

\section{Introduction}

Photodynamic therapy (PDT) has been useful for treating cancer and non-malignant lesions [1,2], especially because it involves a minimally invasive procedure. It is based on the administration of a photosensitizer (PS) in an environment containing oxygen, with further activation by an appropriate light source. The excited triplet state of PS can undergo either type I or type II reactions to produce reactive oxygen species (ROS) [3]. Particularly relevant in PDT, type II reaction results in energy transfer to oxygen, thus forming singlet oxygen $\left({ }^{1} \mathrm{O}_{2}\right)$, a reactive species capable of causing cell death [4]. The short lifetime and diffusion capability of ${ }^{1} \mathrm{O}_{2}$ combined with well controlled irradiation systems may allow locally confined damage, with minimum effect over the adjacent tissue [5]. Therefore, control over PS localization is crucial for the effectiveness of PDT, which has prompted a search for photosensitizers that interact specifically with the target, in addition to having a high quantum yield $\left(\Phi_{\Delta}\right)$ for ${ }^{1} \mathrm{O}_{2}$. Since the first generation of PS based on tetrapyrrole structure [6-9], many synthetic compounds such as chlorins, porphyrins, phenothiazines and xanthene derivatives have been proven efficient in PDT [10,11]. Xanthenes, for instance, have shown not only high $\Phi \Delta^{1} \mathrm{O}_{2}$ but also ability to interact with lipid membranes [12-14], which make them attractive as PS.

Oxidation reactions are the most likely outcome of the interaction between ${ }^{1} \mathrm{O}_{2}$ and biological structures such as DNA, proteins and lipid membranes [4]. Since PS rarely accumulates within the nuclei $[15,16]$, DNA damage by PDT is unlikely. On the other hand, photo-activation of PS localized in the mitochondria and plasma membrane triggers apoptosis [17] and necrosis [18], respectively. Depending on the extent of damage, apoptotic cells can also shift to necrotic, resulting in cell lysis instead of programmed cell death [19]. It is known that hydroperoxidation might be the preferential pathway of lipid oxidation, resulting from the ene reaction with alkenes containing allylic hydrogens [4]. However, the mechanisms underlying the influence of hydroperoxidation over lipid structures are not yet fully understood. Since modifications are found in the membrane permeability, fluidity, packing, and bilayer thickness, there is no consensus in the literature

\footnotetext{
* Corresponding author.

E-mail address: pedro.aoki@unesp.br (P.H.B. Aoki).
} 
about the molecular basis of cellular signaling under lipid oxidation [20-22]. In order to address these mechanisms, one has to resort to suitable methods not only to mimic the cell membrane but also to characterize photochemical reactions at the molecular level. Currently available methods do not afford interrogation of these effects on whole cells, which is the reason why cell membrane models such as Langmuir monolayers have been used extensively [23-30].

In a previous work [31] on the photo-induced modifications of Langmuir monolayers mediated by the xanthene erythrosin B, hydroperoxidation was suggested as the main mechanism of lipid oxidation. Herein, new evidence is presented for hydroperoxidation in lipid monolayers interacting with a different xanthene. Langmuir films of the zwitterionic 1,2-dioleoyl-sn-glycero-3-phosphocholine (DOPC), 1-palmitoyl-2-oleoyl-sn-glycero-3-phosphocholine (POPC) and 1,2-dipalmitoyl-sn-glycero-3-phosphocholine (DPPC) were employed to mimic the first barrier encountered by the xanthene eosin Y dispersed in water. The choice of these lipids was based on the fact that mammalian cell membranes have phosphatidyl cholines as their major components [32]. PS eosin Y has already been applied to photoinactivation of Enterococcus faecalis [33] and Candida albicans [34], having a smaller $\Phi_{\Delta}{ }^{1} \mathrm{O}_{2}$ than erythrosin B. Interestingly, eosin $\mathrm{Y}$ is less cytotoxic in the dark than erythrosin B [35] while having a higher efficiency in decreasing the viability of cancer cells in vitro, according to subsidiary experiments. Therefore, the goal here was to unravel the molecular mechanism of eosin $\mathrm{Y}$ adsorption on lipid membrane and further effects of lipid oxidation triggered by illumination, which might be in the origin of the photodynamic efficiency. While the surface pressure versus area isotherms provided evidence of eosin $\mathrm{Y}$ adsorption and photo-oxidation, the surface specific polarization-modulated infrared reflection-absorption spectroscopy (PM-IRRAS) allowed us to identify the eosin Y binding site and the effects of lipid oxidation on the polar head region of the lipid and in the alkyl chain packing. Experiments of grazing incidence X-ray off-specular scattering (GIXOS) allowed monitoring the monolayer thickness under oxidative stress caused by irradiation of eosin Y.

\section{Experimental section}

\subsection{Materials and solutions}

The xanthene eosin $\mathrm{Y}$ and the zwitterionic phospholipids 1,2-dioleoyl-sn-glycero-3-phosphocholine (DOPC), 1,2-dipalmitoyl-sn-glycero3-phosphocholine (DPPC) and 1-palmitoyl-2-oleoyl-sn-glycero-3-phosphocholine (POPC) were purchased from Sigma-Aldrich. All the materials were used without further purification. Ultrapure water with resistivity $18.2 \mathrm{M} \Omega \mathrm{cm}$ was obtained from a Milli-Q system model Direct$\mathrm{Q}^{\circ}$ 3UV and used to prepare the solutions of eosin $\mathrm{Y}$ at $10^{-5}$ and $10^{-4}$ $\mathrm{mol} / \mathrm{L}$. The molecular structures of DPPC, POPC, DOPC and eosin Y are shown in Fig. 1a.

\subsection{Langmuir films}

Surface pressure $(\pi)$ versus mean molecular area (A) isotherms were obtained in a Langmuir trough (KSV-NIMA / KN 2002). The surface pressure was measured with the Wilhelmy method using a platinum plate. The Langmuir monolayers were prepared by spreading a chloroform (Sigma Aldrich, analytical grade) solution of each phospholipid $\left(1 \times 10^{-3} \mathrm{~mol} / \mathrm{L}\right)$ on the surface of ultrapure water or eosin $\mathrm{Y}$ solution $\left(10^{-5}\right.$ and $\left.10^{-4} \mathrm{~mol} / \mathrm{L}\right)$ as subphase, which were kept at room temperature $\left(23^{\circ} \mathrm{C}\right)$. Chloroform was allowed to evaporate for $15 \mathrm{~min}$ prior to monolayer compression, performed at constant speed of $5 \mathrm{~mm}$ / min. The exposure of unsaturated lipids to the air may trigger oxidation of the monolayer, resulting in fluctuations of surface pressure [36]. No precaution was taken here to prevent oxidation, but the reproducibility of the results was ensured with the observed surface pressure variance within $\pm 2 \mathrm{mN} / \mathrm{m}$ for a given molecular area. The irradiation experiments were performed at constant surface pressure $(30 \mathrm{mN} / \mathrm{m})$ using a green LED (BRIWAX FFG-50 W / ca. $530 \mathrm{~nm}$ ), positioned $15 \mathrm{~mm}$ above the air/water interface, irradiating uniformly the entire area of the Langmuir through $\left(273 \mathrm{~cm}^{2}\right)$, as illustrated in Fig. $1 \mathrm{~b}$.

The polarization-modulated infrared reflection-adsorption spectroscopy (PM-IRRAS) experiments were carried out in a KSV PMI550 (KSV, Finland) trough, using an incidence angle of $81^{\circ}$ with $8 \mathrm{~cm}^{-1}$ of resolution. The incoming light is continuously modulated between s- and p-polarization at a high frequency, allowing simultaneous measurements for the two polarizations [24]. The detected signal gives the differential reflectivity spectrum $\Delta R=(R p-R s) /(R p+R s)$, where $R p$ and Rs are respectively the reflectivities for parallel and perpendicular directions to the plane of incidence [37]. The effect of water vapor is reduced due to the high frequency modulation between $s$ and $p$ polarizations of the incident beam, both simultaneously acquired in the spectra [30,38]. Experiments were performed with phospholipid monolayers on ultrapure water and eosin $\mathrm{Y}\left(10^{-5} \mathrm{~mol} / \mathrm{L}\right)$ subphase at a constant surface pressure of $30 \mathrm{mN} / \mathrm{m}$. The reproducibility of the spectra was assured to guarantee that changes observed are related to the eosin $\mathrm{Y}$ interaction and further membrane hydroperoxidation.

Grazing incidence X-ray off-specular scattering (GIXOS) were performed at the D10B:XRD-2 beamline of the Brazilian Synchrotron Light Laboratory (LNLS). Experiments were performed in phospholipid Langmuir films on ultrapure water and eosin Y $\left(10^{-5} \mathrm{~mol} / \mathrm{L}\right)$ subphase with constant surface pressure $(30 \mathrm{mN} / \mathrm{m})$. The irradiation of the films was carried out as previously mentioned. Basically, the synchrotron horizontal beam (wavelength $\lambda=0.155 \mathrm{~nm}$ ) is vertically deflected so it can reach the air/water interface of the Langmuir trough at a grazing incident angle $\left(\alpha_{i}=0.12^{\circ}\right)$, below the critical angle for total external reflection for water $\left(0.15^{\circ}\right)$. The Langmuir film scatters the incident Xrays creating a scattering pattern which depends on the electronic density of the monolayer. This pattern is acquired using an area detector (Pilatus 300k, Dectris, Switzerland) and the intensity is plotted as function of the scattering vector $\mathrm{q}_{\mathrm{z}}\left(q_{z}=\frac{2 \pi}{\lambda}\left(\sin \alpha_{i}+\sin \alpha_{f}\right)\right.$, where $\alpha_{i}\left(\alpha_{f}\right)$ is the incidence (scattering) angle of the X-ray beam.

\section{Results and discussion}

\subsection{Eosin $Y$ interaction with DPPC, $P O P C$ and DOPC Langmuir monolayers}

The $\pi$-A isotherms for DPPC, POPC and DOPC Langmuir monolayers on ultrapure water and eosin Y solutions $\left(10^{-5}\right.$ and $\left.10^{-4} \mathrm{~mol} / \mathrm{L}\right)$ are displayed in Fig. 2, which also shows that neat eosin is not able to form Gibbs monolayers due to its hydrophilic nature. An increase in eosin Y concentration shifts the $\pi$-A isotherms toward larger molecular areas owing to the eosin-phospholipid interaction. At $10^{-5} \mathrm{~mol} / \mathrm{L}$, this shift for DPPC occurred only in the liquid phase, with the isotherm coinciding with that of a DPPC monolayer on ultrapure water at high surface pressures, in the condensed phase. The eosin Y molecules have been expelled from the DPPC monolayers suggesting that the DPPC-eosin interaction leading to a change in area is not sufficient to withstand high surface pressures. The increased concentration of eosin $\mathrm{Y}\left(10^{-4}\right.$ $\mathrm{mol} / \mathrm{L}$ ) in the subphase favors the interaction with DPPC and a significant displacement is observed in all the compressional stages.

Changes in DOPC and POPC $\pi-\mathrm{A}$ isotherms are noted for the lower eosin $\mathrm{Y}$ concentration $\left(10^{-5} \mathrm{~mol} / \mathrm{L}\right)$, even at high surface pressures. Indeed, the shifts in relative area per lipid $\left[\left(\mathrm{A}-\mathrm{A}_{0}\right) / \mathrm{A}_{0}\right]$ are slightly larger for unsaturated lipids at $10^{-5} \mathrm{~mol} / \mathrm{L}$ concentration, which might indicate stronger interaction (Table 1). The saturated DPPC and unsaturated POPC and DOPC share the same phosphatidylcholine head group. Therefore, the unsaturation in the aliphatic chains of POPC and DOPC is probably responsible for the differences in the interaction with eosin Y. At room temperature $\left(23^{\circ} \mathrm{C}\right)$, both POPC $\left(\mathrm{T}_{\mathrm{m}}=-2{ }^{\circ} \mathrm{C}\right)$ and DOPC $\left(\mathrm{T}_{\mathrm{m}}=-17^{\circ} \mathrm{C}\right)$ are found in the fluid phase, where the chains become more disordered and less packed [36]. The less tight packing should facilitate eosin Y incorporation into the monolayer, similarly to 
(a)

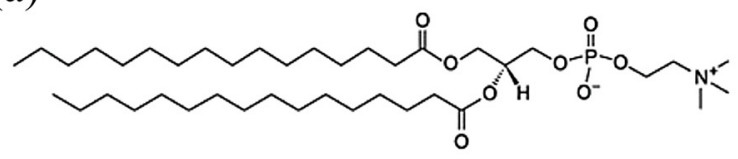

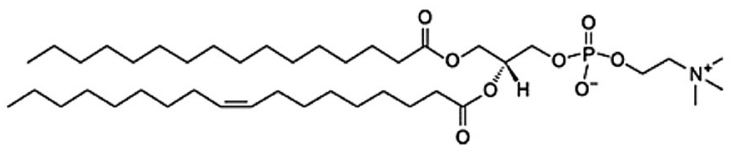

POPC<smiles>CCCCCCCCCCCCCCCCCCCCCCCCC(=O)OCC(=O)OCC(=O)NC(C)(C)COP(=O)(O)OCCN(C)C</smiles>

DOPC<smiles></smiles>

DPPC

Eosin $\mathrm{Y}$

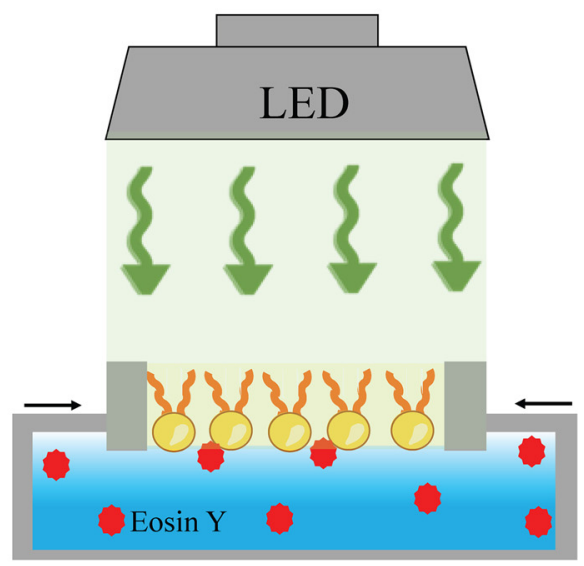

Fig. 1. (a) Molecular structures of eosin Y and zwitterionic phospholipids DPPC, POPC and DOPC. (b) Schematic representation of the setup used for the Langmuir film irradiation.

what was observed for antimicrobial peptides [39,40]. Similar shifts in relative molecular area are observed for all the phospholipids at $10^{-4}$ mol/L, which might indicate a saturation of the number of eosin $\mathrm{Y}$ molecules that actually interact with the monolayer.

The nature of the molecular-level interactions involving eosin $\mathrm{Y}$ was probed with the surface-specific PM-IRRAS method, whose spectra on ultrapure water and eosin $\mathrm{Y}\left(10^{-5} \mathrm{~mol} / \mathrm{L}\right)$ subphase for DPPC and DOPC are shown in Figs. 3 and 4, respectively. The results for POPC are similar to those of DOPC monolayers and will not be shown. The assignments of the main vibrational modes are given in Table 2 along with the shifts induced by eosin Y and further irradiation. Although slight modifications were observed in the surface pressure experiments (Fig. 2a) at $10^{-5} \mathrm{~mol} / \mathrm{L}$ of eosin Y concentration, both head group and tails were affected by eosin Y-DPPC interaction (Fig. 3). The antisymmetric stretching $\mathrm{CN}^{+}\left(\mathrm{CH}_{3}\right)_{3}$ shifted from 964 to $944 \mathrm{~cm}^{-1}$, suggesting that electrostatic interactions should bring the anionic eosin $\mathrm{Y}$ [41] to the surroundings of the positively charged choline group (Fig. 3b). The symmetric $\mathrm{P}=\mathrm{O}$ stretching $\mathrm{v}_{\mathrm{s}}\left(\mathrm{PO}_{2}{ }^{-}\right)$at $1080 \mathrm{~cm}^{-1}$ shifted to $1100 \mathrm{~cm}^{-1}$ while the $\mathrm{C}-\mathrm{O}-\mathrm{PO}_{2}$ stretching at $1057 \mathrm{~cm}^{-1}$ had its intensity significantly increased. Changes in the vibrational modes of phosphate groups suggest that $\mathrm{H}$-bonding with the surrounding water molecules was affected by eosin $[42,37]$. The $\nu(C=O)$ stretching is centered at $1735 \mathrm{~cm}^{-1}$, but the exact position depends on the hydration of the head groups and the polarity of the medium. Eosin Y shifts $\nu(C=O)$ from $1735 \mathrm{~cm}^{-1}$ to $1727 \mathrm{~cm}^{-1}$, which is evidence of hydrated carbonyl ester
Table 1

Relative shifts in the mean molecular area $\left[\left(\mathrm{A}-\mathrm{A}_{0}\right) / \mathrm{A}_{0}\right]$ at $30 \mathrm{mN} / \mathrm{m} . \mathrm{A}_{0}$ and $\mathrm{A}$ are the extrapolated areas for ultrapure water and eosin $\mathrm{Y}$ solutions $\left(10^{-4}\right.$ and $\left.10^{-5} \mathrm{~mol} / \mathrm{L}\right)$, respectively.

\begin{tabular}{llll}
\hline \multirow{2}{*}{$\begin{array}{l}\text { Eosin Y concentration } \\
\mathrm{mol} / \mathrm{L}\end{array}$} & \multicolumn{2}{l}{ Relative Shift } & \\
\cline { 2 - 4 } & DPPC & POPC & DOPC \\
\hline $10^{-4}$ & 0.37 & 0.34 & 0.36 \\
$10^{-5}$ & 0.04 & 0.09 & 0.06 \\
\hline
\end{tabular}

groups [43], similarly to reports for monovalent ions and other photosensitizers [44]. Changes in the $\mathrm{CH}_{2}$ stretching are illustrated on the right panel in Fig. 3a and suggest little penetration of eosin $\mathrm{Y}$ molecules into hydrophobic chains [45]. The $v_{s}\left(\mathrm{CH}_{2}\right)$ at $2847 \mathrm{~cm}^{-1}$ shifted to $2855 \mathrm{~cm}^{-1}$ while $v_{\text {as }}\left(\mathrm{CH}_{2}\right)$ remained unaltered at $2924 \mathrm{~cm}^{-1}$. The intensity ratio between the symmetric $\left(\mathrm{I}_{\mathrm{s}}, 2847 \mathrm{~cm}^{-1}\right)$ and antisymmetric $\mathrm{CH}_{2}$ stretching $\left(\mathrm{I}_{\mathrm{as}}, 2924 \mathrm{~cm}^{-1}\right.$ ) decreased from 0.54 to 0.31 , thus indicating an increased order of the hydrocarbon chains owing to eosin $\mathrm{Y}$ [45]. Although similar findings were reported for other dyes with the ability to organize lipid monolayers [46], this behavior is opposite to the increased disorder of DPPC chains in monolayers interacting with erythrosin B [31]. Given the higher electrophilic character of erythrosin B [35], stronger electrostatic interactions could have been established with the monolayer headgroups, capable of causing an increased
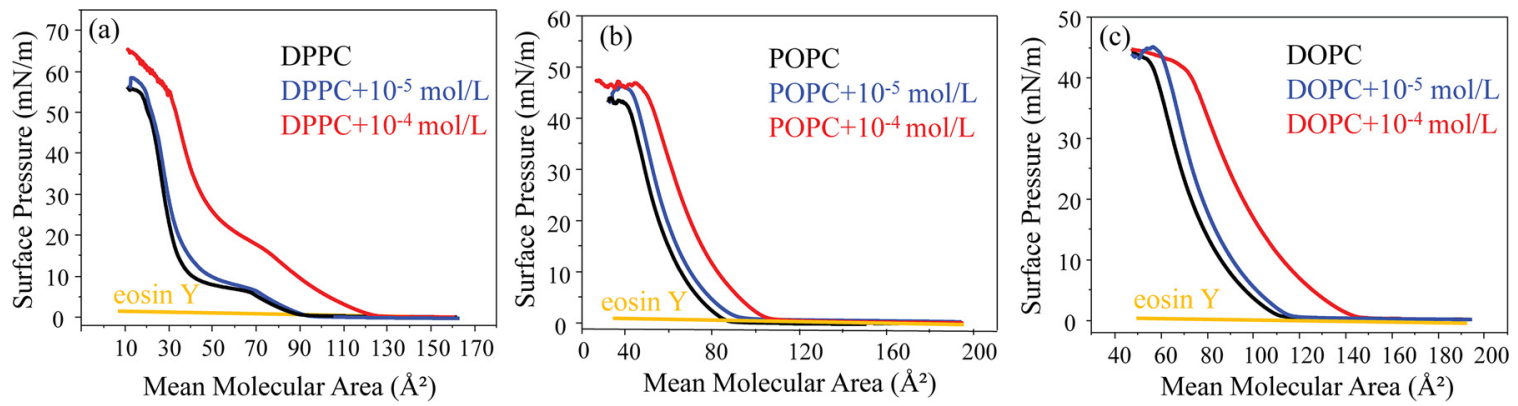

Fig. 2. $\pi$-A isotherms for (a) DPPC, (b) POPC and (c) DOPC Langmuir monolayers on ultrapure water and eosin $\mathrm{Y}$ solutions $\left(10^{-5}\right.$ and $\left.10^{-4} \mathrm{~mol} / \mathrm{L}\right)$. 


\section{(a) PM-IRRAS spectra of DPPC monolayers}
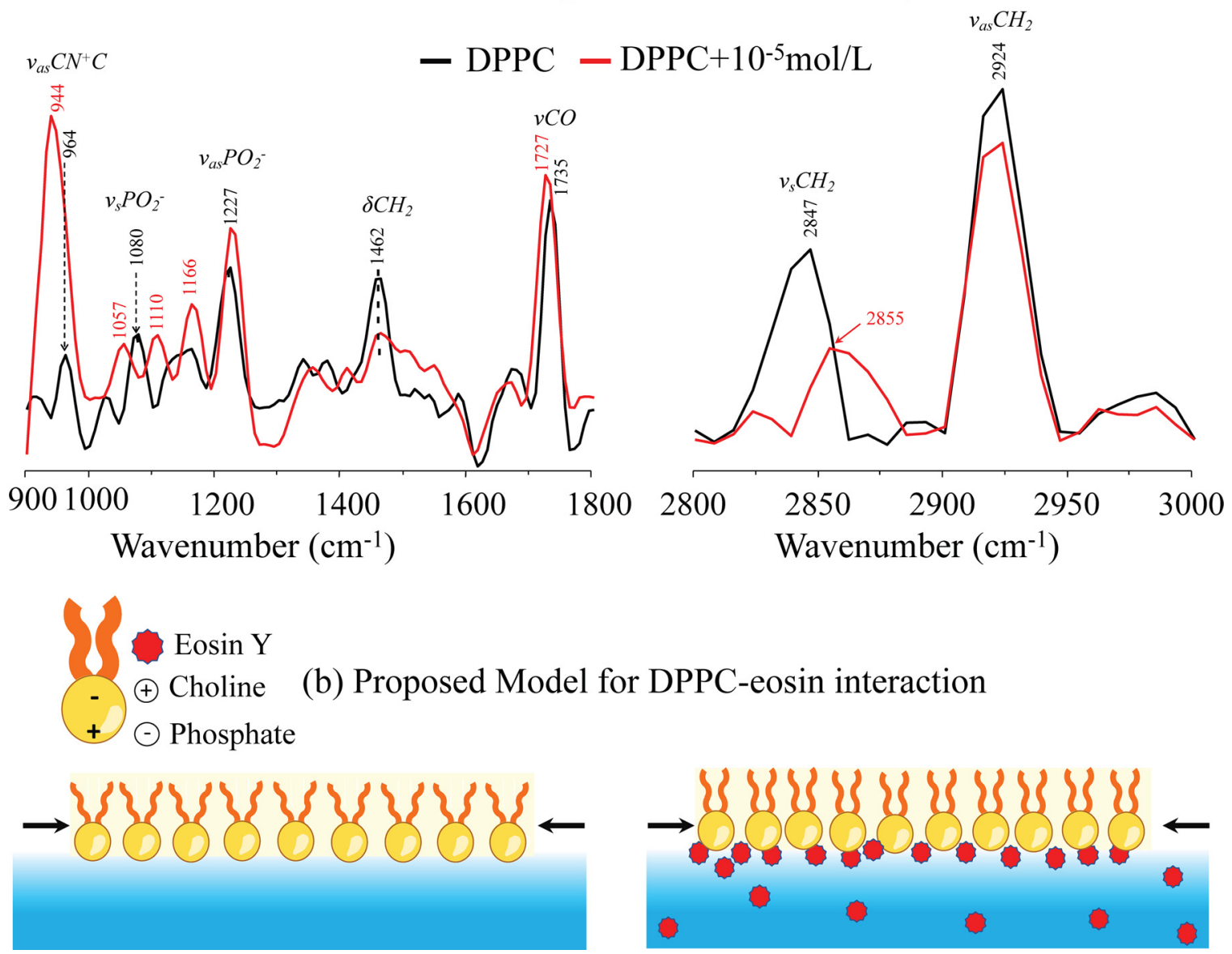

Fig. 3. (a) PM-IRRAS spectra of DPPC monolayers acquired at constant surface pressure $(30 \mathrm{mN} / \mathrm{m})$ on ultrapure water and eosin $\mathrm{Y}\left(10^{-5} \mathrm{~mol} / \mathrm{L}\right) \mathrm{subphase}$. (b) proposed model for DPPC-eosin interaction. The DPPC monolayer at the air/water interface and upon eosin Y interaction is depicted on the left and right panel, respectively. The positive and negative signs in phospholipid heads represent the choline and phosphate groups, respectively.

disorder of the monolayer chains. The weaker interactions might have limited eosin $\mathrm{Y}$ adsorption to the choline groups, forming a headgroup sublayer which would induce order in the hydrophobic tails. Indeed, Eosin $\mathrm{Y}$ at $10^{-5} \mathrm{~mol} / \mathrm{L}$ caused almost no change in the isotherm and the ordering in the lipid tails would counterbalance the expected increase in area per molecule with eosin Y adsorption. Fig. 3b depicts the proposed model for eosin Y interacting with DPPC monolayer, based on the surface pressure and PM-IRRAS data.

The interaction between eosin Y and DOPC differs from that of DPPC, mainly due to the unsaturation of the DOPC chains, consistent with the surface pressure data. For instance, the intensity of the choline group $\nu_{\text {as }}\left(\mathrm{CN}^{+}\left(\mathrm{CH}_{3}\right)_{3}\right)$ at $971 \mathrm{~cm}^{-1}$ was significantly reduced by electrostatic interaction with eosin $\mathrm{Y}$, as shown on the left panel of Fig. 4a. The $v_{\mathrm{s}}\left(\mathrm{PO}_{2}{ }^{-}\right)$at $1079 \mathrm{~cm}^{-1}$ shifted to $1088 \mathrm{~cm}^{-1}$ while the $\mathrm{C}-\mathrm{O}-\mathrm{PO}_{2}{ }^{-}$stretching at $1034 \mathrm{~cm}^{-1}$ shifted to $1057 \mathrm{~cm}^{-1}$. The vibrational modes of phosphate group are amenable to H-bonding with the surrounding water molecules and eosin $\mathrm{Y}$ appears to have disrupted it, as it occurs for DPPC monolayers. Also interesting is the increased intensity of the band at $1532 \mathrm{~cm}^{-1}$ assigned to the xanthene ring stretching [47], which shows that eosin Y molecules coming from the aqueous subphase penetrate into the DOPC monolayer. The small bands between $1600-1700 \mathrm{~cm}^{-1}$ should be attributed to the difference in reflectivity of the water interface when covered with the monolayer. The bands of the alkyl chains within $2800-3000 \mathrm{~cm}^{-1}$ are displayed on the right panel of Fig. 4a. The $\mathrm{v}(\mathrm{HC}=\mathrm{CH})$ stretching appears at 2992 $\mathrm{cm}^{-1}$ while the antisymmetric $\mathrm{v}_{\mathrm{as}}\left(\mathrm{CH}_{2}\right)$ and symmetric $\mathrm{v}_{\mathrm{s}}\left(\mathrm{CH}_{2}\right)$ stretching are found at 2929 and $2847 \mathrm{~cm}^{-1}$, respectively. Eosin Y adsorption shifts $v_{\mathrm{s}}\left(\mathrm{CH}_{2}\right)$ to $2866 \mathrm{~cm}^{-1}$. Furthermore, the $\mathrm{I}_{\mathrm{s}} / \mathrm{I}_{a s}$ ratio increased from 0.22 to 0.33 which means a decreased order of the monolayer chains [48]. Taking these results together with the increased intensity of $\nu_{\text {as }}\left(\mathrm{CH}_{3}\right)$ stretching at $2964 \mathrm{~cm}^{-1}$ and the shift of $\mathrm{v}(\mathrm{HC}=\mathrm{CH})$ to $3025 \mathrm{~cm}^{-1}$, one may conclude that modifications induced by eosin $\mathrm{Y}$ are more drastic on DOPC than for DPPC monolayers. Although the modifications in the PM-IRRAS spectra of DOPC may suggest penetration of eosin $\mathrm{Y}$ into the aliphatic chains, it may not be as strong as observed for erythrosin B [31]. Due to the higher lipophilic character, erythrosin B has been efficient in penetrating DOPC chains $[35,49]$, which might have decreased the repulsion over the unsaturations and increased the chain order. It is presumable that eosin Y could be inserted up to the phosphate region of the head groups, with less penetration into the aliphatic chains. Therefore, the electrostatic repulsion of the unsaturated chains is not decreased, and the presence of eosin Y contributes to a smaller chain order, as depicted in Fig. 4b.

We note that the PM-IRRAS spectra were taken only for the $10^{-5}$ $\mathrm{mol} / \mathrm{L}$ because we found in subsidiary cell culture experiments that the effects of this concentration were equally large to those of the higher $10^{-4} \mathrm{~mol} / \mathrm{L}$ concentration. Also, eosin Y exhibited higher photodynamic efficiency than erythrosin B. With the experiments using Langmuir films, we cannot establish unequivocally the reason for this difference in photodynamic efficiency, particularly because experiments involving membrane permeability could be required. Nevertheless, the different interaction mechanisms between eosin $\mathrm{Y}$ and erythrosin B with lipid membranes might be in the origin of the photodynamic efficiency. 


\section{(a) PM-IRRAS spectra of DOPC monolayers}

\section{- DOPC $-\mathrm{DOPC}+10^{-5} \mathrm{~mol} / \mathrm{L}-\mathrm{DOPC}+10^{-5} \mathrm{~mol} / \mathrm{L}$ irradiated}
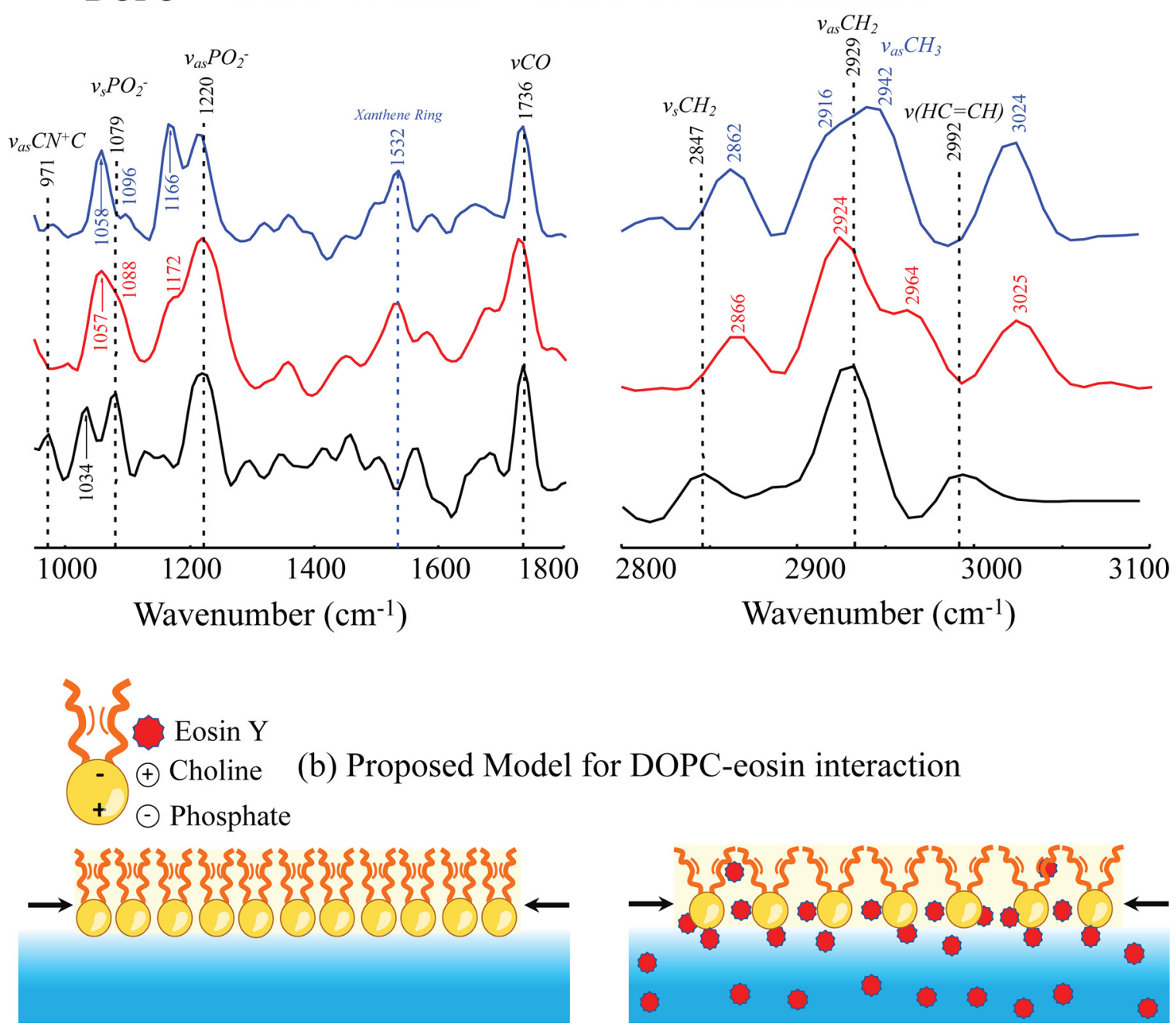

Fig. 4. (a) PM-IRRAS spectra of DOPC monolayers at a surface pressure of $30 \mathrm{mN} / \mathrm{m}$ on ultrapure water and eosin $\mathrm{Y}\left(10^{-5} \mathrm{~mol} / \mathrm{L}\right)$ subphase before and after irradiation. (b) proposed model for DOPC-eosin Y interaction. A pictorial view of the structuring of DOPC molecules at the air/water interface and upon eosin Y interaction is depicted on the left and right panel, respectively. The positive and negative signs in phospholipid heads represent the choline and phosphate groups, respectively. The spectra were shifted vertically - with baselines at distinct levels - to facilitate visualization.

Table 2

Assignments of the main vibrational modes in DPPC and DOPC spectra along with the shifts induced by eosin Y and further irradiation.

\begin{tabular}{|c|c|c|c|c|c|}
\hline \multicolumn{2}{|c|}{ DPPC $\left(\mathrm{cm}^{-1}\right)$} & \multicolumn{3}{|c|}{ DOPC $\left(\mathrm{cm}^{-1}\right)$} & \multirow[t]{2}{*}{ Assignment } \\
\hline DPPC & $\mathrm{DPPC}+$ eosin & DOPC & $\mathrm{DOPC}+$ eosin & $\mathrm{DOPC}+$ eosin + irradiation & \\
\hline \multirow[t]{2}{*}{-} & - & 2992 & 3025 & 3024 & $v(\mathrm{HC}=\mathrm{CH})$ \\
\hline & & - & 2964 & 2942 & $\mathrm{v}_{\mathrm{as}}\left(\mathrm{CH}_{3}\right)$ \\
\hline 2924 & 2924 & 2929 & 2924 & 2916 & $\mathrm{v}_{\mathrm{as}}\left(\mathrm{CH}_{2}\right)$ \\
\hline 2847 & 2855 & 2847 & 2866 & 2862 & $\mathrm{v}_{\mathrm{s}}\left(\mathrm{CH}_{2}\right)$ \\
\hline 1735 & 1727 & 1736 & 1729 & 1736 & $v(C=O)$ \\
\hline 1462 & 1462 & - & - & - & $\delta\left(\mathrm{CH}_{2}\right)$ \\
\hline 1227 & 1227 & 1220 & 1220 & 1215 & $\mathrm{v}_{\mathrm{as}}\left(\mathrm{PO}_{2}^{-}\right)$ \\
\hline 1166 & 1166 & 1170 & 1172 & 1166 & $\mathrm{v}_{\mathrm{as}}(\mathrm{C}-\mathrm{O}-\mathrm{C})$ \\
\hline 1080 & 1110 & 1079 & 1088 & 1096 & $\mathrm{v}_{\mathrm{s}}\left(\mathrm{PO}_{2}{ }^{-}\right)$ \\
\hline 1057 & 1057 & 1034 & 1057 & 1058 & $\mathrm{v}\left(\mathrm{C}-\mathrm{O}-\mathrm{PO}_{2}^{-}\right)$ \\
\hline 964 & 944 & 971 & 979 & 977 & $\nu_{\text {as }}\left(\mathrm{CN}^{+}\left(\mathrm{CH}_{3}\right)_{3}\right)$ \\
\hline
\end{tabular}



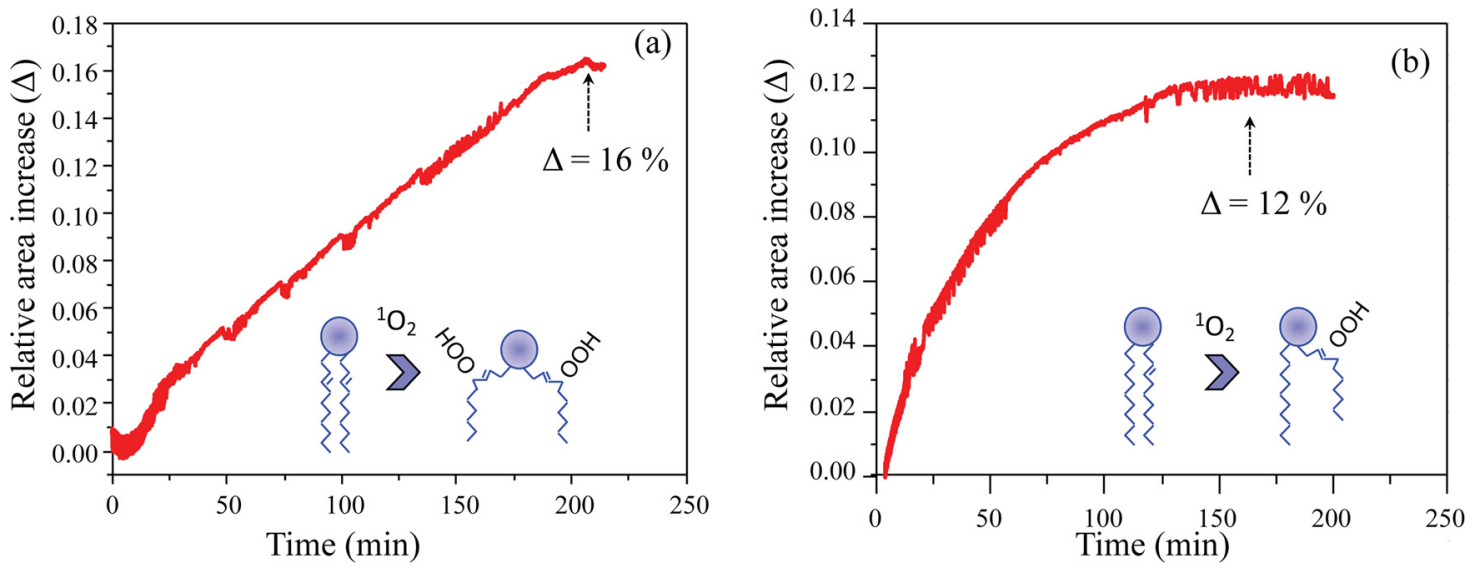

Fig. 5. Relative increase [ $\Delta=$ (irradiated monolayer) - (non-irradiated monolayer)] in molecular area of (a) DOPC and (b) POPC monolayers at $30 \mathrm{mN} / \mathrm{m}$.

\subsection{Photosensitization of the Langmuir monolayers}

The photo-oxidation effects over the membrane properties were evaluated by irradiating $(\lambda=530 \mathrm{~nm})$ the DPPC, POPC and DOPC Langmuir films on $10^{-5} \mathrm{~mol} / \mathrm{L}$ of eosin Y subphase. Experiments were limited to this concentration (not including $10^{-4} \mathrm{~mol} / \mathrm{L}$ ) for the same reason given above. In control experiments we noted that the neat DPPC, POPC and DOPC monolayers (on ultrapure water, no eosin Y included) are not affected by irradiation. The surface area of the irradiated and non-irradiated monolayers was monitored at a constant surface pressure of $30 \mathrm{mN} / \mathrm{m}$ for these monolayers on an eosin-containing subphase. DPPC monolayers (results not shown) were not affected by irradiation, unlike POPC and DOPC monolayers. A significant trend of surface area decrease (Fig. SI1) is observed over time for both POPC and DOPC non-irradiated films, which might be related to loss of material to the subphase triggered by monolayer oxidation by reactive species in the air [50]. The slope of the curves is inverted under irradiation suggesting an increased area per phospholipid molecule. The net effect of relative area increase $[\Delta=$ (irradiated monolayer) - (nonirradiated monolayer)] for POPC and DOPC monolayers is plotted in Fig. 5a and b, respectively. Under irradiation, eosin Y generates singlet oxygen $\left({ }^{1} \mathrm{O}_{2}\right)$, a reactive specie capable of oxidizing biological targets [51]. Reactions of ${ }^{1} \mathrm{O}_{2}$ with the unsaturated bonds of the lipid chains generate hydroperoxide $-\mathrm{OOH}$ groups, which are hydrophilic and can migrate toward the polar head groups of the lipid [20,52-57]. Larger molecular areas are occupied by hydroperoxidized lipids, which may be the explanation for the overall surface area increase. The relative area increase of ca. $16 \%$ for DOPC is slightly larger than the ca. $12 \%$ for POPC monolayers. The origin of this difference is the presence of one unsaturated bond in both DOPC hydrocarbon chains, compared to only one unsaturated chain in POPC. The latter suggests that a fully hydroperoxidized DOPC monolayer has, on average, more hydroperoxide groups in the vicinity of the monolayer-water interface. Compared to erythrosin B [31,52], the relative surface area increase induced by photo-activated eosin $\mathrm{Y}$ is slightly smaller, which can be explained by the lower ${ }^{1} \mathrm{O}_{2}$ quantum yield ( $\Phi \Delta_{\text {erytrosin }} \sim 0,62$ and $\Phi \Delta_{\text {eosin }} \sim 0,59$ ) [49].

Irradiation of DOPC monolayer containing eosin $\mathrm{Y}$ induces significant changes in the PM-IRRAS spectra, as shown in Fig. 4, unlike DPPC monolayers. For instance, the relative intensity of the o(C-O$\left.\mathrm{PO}_{2}{ }^{-}\right)$at $1058 \mathrm{~cm}^{-1}$ increased in relation to $\nu_{\mathrm{s}}\left(\mathrm{PO}_{2}{ }^{-}\right)$, and shifted from 1088 to $1096 \mathrm{~cm}^{-1}$. Analogously, the relative intensity of $\mathrm{v}_{\mathrm{as}}(\mathrm{C}-\mathrm{O}-\mathrm{C})$ at $1166 \mathrm{~cm}^{-1}$ increased compared to that of $\nu_{\text {as }}\left(\mathrm{PO}_{2}{ }^{-}\right)$at $1220 \mathrm{~cm}^{-1}$. Changes in the $\mathrm{P}=\mathrm{O}$ vibrational modes indicate that $\mathrm{H}$-bonding between phosphate groups and water molecules is affected. In addition, hydroperoxide-containing lipids are likely to form hydrogen bonds with phosphate groups, which is consistent with the presence of hydroperoxides at the monolayer/water interface [56]. The xanthene ring band at $1532 \mathrm{~cm}^{-1}$ appears to indicate that eosin $\mathrm{Y}$ molecules remain at the monolayer, even after hydroperoxidation. Regarding the hydrophobic chains, $v_{\text {as }}\left(\mathrm{CH}_{2}\right)$ stretching shifted from 2924 to $2916 \mathrm{~cm}^{-1}$ and had the relative intensity decreased compared to $v_{\text {as }}\left(\mathrm{CH}_{3}\right)$ at $2942 \mathrm{~cm}^{-1}$. It is worth mentioning that propagation of hydroperoxidation reaction may lead to the cleavage of the aliphatic chain near the original position of the unsaturation $[22,58-60]$. However, the $\mathrm{v}(\mathrm{HC}=\mathrm{CH})$ band at 3024 $\mathrm{cm}^{-1}$ indicates that this was not the case and most of the chains remain uncleaved.

Further evidence of lipid hydroperoxidation arises from the change in monolayer thickness as the area per phospholipid increased [21,61]. Fig. 6 displays the grazing incidence X-ray off-specular scattering (GIXOS) for DPPC, POPC and DOPC Langmuir monolayers on $10^{-5}$ $\mathrm{mol} / \mathrm{L}$ of eosin Y subphase before and after irradiation. The position of the first minimum in the GIXOS signal $\left(\mathrm{q}_{\mathrm{z}}{ }^{\text {mín }}\right)$ corresponds to destructive interference of the light scattered in the polar heads and aliphatic chains of the monolayer. The distance from the air/alkyl chain interface until the maximum electronic density of the polar heads can be
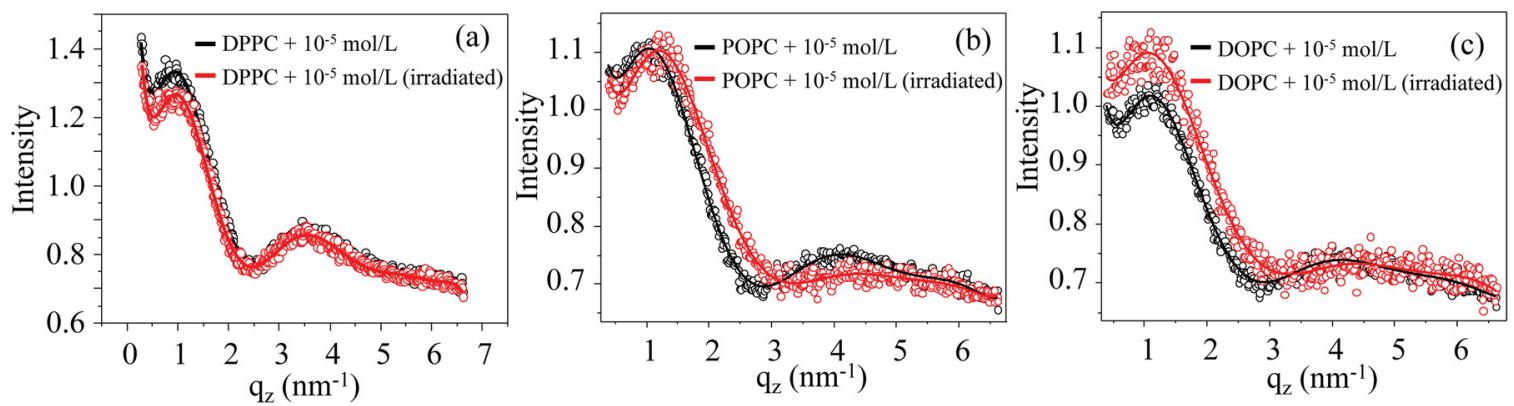

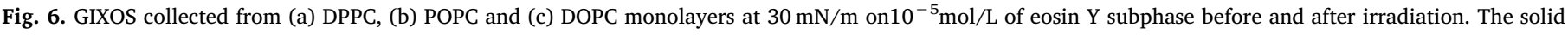
lines correspond to the data fitting with Savitzky Golay. 
Table 3

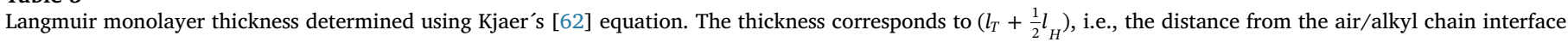
until the central position of the headgroup region.

\begin{tabular}{|c|c|c|c|c|c|c|c|c|}
\hline \multicolumn{9}{|c|}{ Langmuir monolayers at $30 \mathrm{mN} / \mathrm{m}$} \\
\hline \multicolumn{3}{|l|}{ DPPC } & \multicolumn{3}{|l|}{ POPC } & \multicolumn{3}{|l|}{ DOPC } \\
\hline $\begin{array}{l}\text { Eosin Y } \\
(\mathrm{mol} / \mathrm{L})\end{array}$ & $q_{z}^{\min }(\mathrm{nm})$ & Thickness (nm) & $\begin{array}{l}\text { Eosin Y } \\
(\mathrm{mol} / \mathrm{L})\end{array}$ & $q_{z}^{\min }(\mathrm{nm})$ & Thickness (nm) & $\begin{array}{l}\text { Eosin Y } \\
(\mathrm{mol} / \mathrm{L})\end{array}$ & $q_{z}^{\min }(\mathrm{nm})$ & Thickness (nm) \\
\hline $10^{-5}$ & 2.48 & 1.90 & $10^{-5}$ & 2.90 & 1.62 & $10^{-5}$ & 2.93 & 1.60 \\
\hline $10^{-5}$ irradiated & 2.46 & 1.91 & $10^{-5}$ irradiated & 3.38 & 1.39 & $10^{-5}$ irradiated & 3.35 & 1.40 \\
\hline
\end{tabular}

calculated with Kjaer's [62] equation:

$q_{z}^{\text {min }} \cong \frac{3 \pi}{2\left(l_{T}+\frac{1}{2} l_{H}\right)}$

where $l_{\mathrm{T}}$ and $\mathrm{l}_{\mathrm{H}}$ are the thicknesses of hydrocarbon chains and polar head group, respectively. The latter approach provides an approximation of film thickness, valid for monolayers made of amphiphilic molecules. While DPPC monolayers in Fig. 6a are not affected by eosin Y photo-activation, the position of $\mathrm{q}_{\mathrm{z}}^{\min }$ is displaced toward larger values for POPC (Fig. 6b) and DOPC (Fig. 6c) films, indicating a decrease in monolayer thickness (cf. Table 3). The correlation between surface area increase and decrease in membrane thickness is certainly not straightforward, but the experimental evidence of lipid hydroperoxidation reported here agrees with the pioneering molecular dynamics (MD) simulations of lipid bilayers containing oxidized phospholipids [56].

\section{Conclusions}

Simplified models of cell membranes based on Langmuir monolayers combined with the surface-specific PM-IRRAS technique allowed us to access the molecular mechanism of interaction between eosin $\mathrm{Y}$ and zwitterionic DPPC, POPC and DOPC phospholipid monolayers. Electrostatic interactions with the positively charged choline groups in the phospholipid head groups favored adsorption of the anionic eosin Y. The less packed DOPC and POPC monolayers allowed penetration of eosin $\mathrm{Y}$ into the monolayer, favoring further singlet oxygen $\left({ }^{1} \mathrm{O}_{2}\right)$ generation in the vicinity of the double bonds, which is essential for photodynamic efficiency. Upon irradiation, the increase in surface area inferred from $\pi$-A isotherms of DOPC and POPC monolayers is consistent with the reaction between ${ }^{1} \mathrm{O}_{2}$ and unsaturations leading to hydroperoxide formation. Indeed, the shifts in PM-IRRAS bands in both head group and aliphatic chain vibrational modes agree with the migration of hydroperoxides from the hydrophobic core of the membrane toward the water/monolayer interface. Also consistent with lipid hydroperoxidation is the decrease in membrane thickness inferred from GIXOS measurements for DOPC and POPC monolayers. Taken together, these results shed light on the molecular mechanisms of cell membrane photo-oxidation, which is relevant not only for photodynamic therapy (PDT) applications but also for many other fields of life sciences and health.

\section{Acknowledgments}

We acknowledge funding provided by FAPESP (2017/13404-3, 2016/13280-0, 2013/14262-7) and CNPq (403713/2016-1). We thank Anderson Fiamingo, Bianca Sandrino and Diego Semissatto for the support with the GIXOS experiments. We also acknowledge LNLS for beamtime at XRD-2 beamline, under proposal number 20160718.

\section{Appendix A. Supplementary data}

Supplementary material related to this article can be found, in the online version, at doi:https://doi.org/10.1016/j.colsurfb.2018.08.002.

\section{References}

[1] D.E.J.G.J. Dolmans, D. Fukumura, R.K. Jain, Photodynamic therapy for cancer, Nat. Rev. Cancer 3 (2003) 380-387, https://doi.org/10.1038/nrc1070.

[2] L. Mohammad-Hadi, A.J. MacRobert, M. Loizidou, E. Yaghini, Photodynamic therapy in 3D cancer models and the utilisation of nanodelivery systems, Nanoscale 10 (2018) 1570-1581, https://doi.org/10.1039/c7nr07739d.

[3] H. Ding, H. Yu, Y. Dong, R. Tian, G. Huang, D.A. Boothman, B.D. Sumer, J. Gao, Photoactivation switch from type II to type I reactions by electron-rich micelles for improved photodynamic therapy of cancer cells under hypoxia, J. Control. Release 156 (2011) 276-280, https://doi.org/10.1016/J.JCONREL.2011.08.019.

[4] I.O.L. Bacellar, T.M. Tsubone, C. Pavani, M.S. Baptista, Photodynamic efficiency: from molecular photochemistry to cell death, Int. J. Mol. Sci. 16 (2015) 20523-20559, https://doi.org/10.3390/ijms160920523.

[5] R. Yin, T. Agrawal, U. Khan, G.K. Gupta, V. Rai, Y.-Y. Huang, M.R. Hamblin, Antimicrobial photodynamic inactivation in nanomedicine: small light strides against bad bugs, Nanomedicine 10 (2015) 2379-2404, https://doi.org/10.2217/ nnm.15.67.

[6] U.O. Nseyo, J. DeHaven, T.J. Dougherty, W.R. Potter, D.L. Merrill, S.L. Lundahl, D.L. Lamm, Photodynamic therapy (PDT) in the treatment of patients with resistant superficial bladder cancer: a long-term experience, J. Clin. Laser Med. Surg. 16 (1998) 61-68 http://www.ncbi.nlm.nih.gov/pubmed/9728133.

[7] Z. Huang, A review of progress in clinical photodynamic therapy, Technol. Cancer Res. Treat. 4 (2005) 283-293, https://doi.org/10.1177/153303460500400308.

[8] A. Orenstein, G. Kostenich, L. Roitman, Y. Shechtman, Y. Kopolovic, B. Ehrenberg, Z. Malik, A comparative study of tissue distribution and photodynamic therapy selectivity of chlorin e6, Photofrin II and ALA-induced protoporphyrin IX in a colon carcinoma model, Br. J. Cancer 73 (1996) 937-944 (accessed December 25, 2017), http://www.ncbi.nlm.nih.gov/pubmed/8611429.

[9] D. Kessel, P. Thompson, Purification and analysis of hematoporphyrin and hematoporphyrin derivative by gel exclusion and reverse-phase chromatography, Photochem. Photobiol. 46 (1987) 1023-1025 (Accessed 31 December 2017), http://www.ncbi.nlm.nih.gov/pubmed/2964039.

[10] M.J. Bovis, J.H. Woodhams, M. Loizidou, D. Scheglmann, S.G. Bown, A.J. MacRobert, Improved in vivo delivery of m-THPC via pegylated liposomes for use in photodynamic therapy, J. Control. Release 157 (2012) 196-205, https://doi. org/10.1016/J.JCONREL.2011.09.085.

[11] B.J. Qumseya, W. David, H.C. Wolfsen, Photodynamic therapy for Barrett's esophagus and esophageal carcinoma, Clin. Endosc. 46 (2013) 30, https://doi.org/10. 5946/ce.2013.46.1.30.

[12] P.C. de S. Pereira, P.F. do A. Costa, D.S. Pellosi, I.R. Calori, B.H. Vilsinski, B.M. Estevão, N. Hioka, W. Caetano, Photophysical properties and interaction studies of Rose Bengal derivatives with biomimetic systems based in micellar aqueous solutions, J. Mol. Liq. 230 (2017) 674-685, https://doi.org/10.1016/J. MOLLIQ.2017.01.055.

[13] I.R. Calori, D.S. Pellosi, D. Vanzin, G.B. Cesar, P.C.S. Pereira, M.J. Politi, N. Hioka, W. Caetano, Distribution of xanthene dyes in DPPC vesicles: rationally accounting for drug partitioning using a membrane model, J. Braz. Chem. Soc. 27 (2016) 1938-1948, https://doi.org/10.5935/0103-5053.20160079.

[14] B.M. Estevão, D.S. Pellosi, C.F. de Freitas, D. Vanzin, D.S. Franciscato, W. Caetano, N. Hioka, Interaction of eosin and its ester derivatives with aqueous biomimetic micelles: evaluation of photodynamic potentialities, J. Photochem. Photobiol. A Chem. 287 (2014) 30-39, https://doi.org/10.1016/j.jphotochem.2014.04.015.

[15] T.A. Slastnikova, A.A. Rosenkranz, T.N. Lupanova, P.V. Gulak, N.V. Gnuchev, A.S. Sobolev, Study of efficiency of the modular nanotransporter for targeted delivery of photosensitizers to melanoma cell nuclei in vivo, Dokl. Biochem. Biophys. 446 (2012) 235-237, https://doi.org/10.1134/S1607672912050146.

[16] A.E. O'Connor, W.M. Gallagher, A.T. Byrne, Porphyrin and nonporphyrin photosensitizers in oncology: preclinical and clinical advances in photodynamic therapy, Photochem. Photobiol. 85 (2009) 1053-1074, https://doi.org/10.1111/j.1751 1097.2009.00585.x.

[17] D. Kessel, Apoptosis and associated phenomena as a determinants of the efficacy of photodynamic therapy, Photochem. Photobiol. Sci. 14 (2015) 1397-1402, https:// doi.org/10.1039/C4PP00413B.

[18] D. Kessel, N.L. Oleinick, Photodynamic therapy and cell death pathways, Methods Mol. Biol. (2010) 35-46, https://doi.org/10.1007/978-1-60761-697-9_3. 
[19] S. Marchal, A. Fadloun, E. Maugain, M.-A. D’Hallewin, F. Guillemin, L. Bezdetnaya, Necrotic and apoptotic features of cell death in response to Foscan ${ }^{\circledast}$ photosensitization of HT29 monolayer and multicell spheroids, Biochem. Pharmacol. 69 (2005) 1167-1176, https://doi.org/10.1016/J.BCP.2005.01.021.

[20] Wilker Caetano, Paula S. Haddad, Rosangela Itri, Divinomar Severino, ViniciusC. Vieira, Mauricio S. Baptista, AndréP. Schröder, C.M. Marques, PhotoInduced Destruction of Giant Vesicles in Methylene Blue Solutions, (2006), https:// doi.org/10.1021/LA061510V.

[21] L. Cwiklik, P. Jungwirth, Massive oxidation of phospholipid membranes leads to pore creation and bilayer disintegration, Chem. Phys. Lett. 486 (2010) 99-103, https://doi.org/10.1016/J.CPLETT.2010.01.010.

[22] O. Mertins, I.O.L. Bacellar, F. Thalmann, C.M. Marques, M.S. Baptista, R. Itri, Physical damage on giant vesicles membrane as a result of methylene blue photoirradiation, Biophys. J. 106 (2014) 162-171, https://doi.org/10.1016/j.bpj.2013. 11.4457.

[23] L.F.G. Salis, G.N. Jaroque, J.F.B. Escobar, C. Giordani, A.M. Martinez D.M.M. Fernández, F. Castelli, M.G. Sarpietro, L. Caseli, Interaction of $3^{\prime}, 4^{\prime}, 6^{\prime}$-trimyristoyl-uridine derivative as potential anticancer drug with phospholipids of tumorigenic and non-tumorigenic cells, Appl. Surf. Sci. 426 (2017) 77-86, https:// doi.org/10.1016/J.APSUSC. 2017.07.094.

[24] R.L. Cruz Gomes da Silva, H.F. Oliveira da Silva, L.H. da, Silva Gasparotto, L. Caseli, How the interaction of PVP-stabilized Ag nanoparticles with models of cellular membranes at the air-water interface is modulated by the monolayer composition, J. Colloid Interface Sci. 512 (2018) 792-800, https://doi.org/10.1016/j.jcis.2017. 10.091.

[25] F.A. Scholl, P.V. Morais, R.C. Gabriel, M.J. Schöning, J.R. Siqueira, L. Caseli, Carbon Nanotubes arranged as smart interfaces in lipid Langmuir-blodgett films enhancing the enzymatic properties of penicillinase for biosensing applications, ACS Appl. Mater. Interfaces 9 (2017) 31054-31066, https://doi.org/10.1021/ acsami.7b08095.

[26] A.P. Girard-Egrot, S. Godoy, L.J. Blum, Enzyme association with lipidic Langmuir-Blodgett films: interests and applications in nanobioscience, Adv. Colloid Interface Sci. 116 (2005) 205-225, https://doi.org/10.1016/j.cis.2005.04.006.

[27] L Caseli, M.E.D. Zaniquelli, R.P.M. Furriel, F.A. Leone, Enzymatic activity of alkaline phosphatase adsorbed on dimyristoylphosphatidic acid Langmuir-Blodgett films, Colloids Surf. B Biointerfaces 25 (2002) 119-128, https://doi.org/10.1016/ S0927-7765(01)00302-2.

[28] T.F. Schmidt, L. Caseli, O.N. Oliveira, R. Itri, Binding of methylene blue onto langmuir monolayers representing cell membranes may explain its efficiency as photosensitizer in photodynamic therapy, Langmuir 31 (2015) 4205-4212, https:// doi.org/10.1021/acs.langmuir.5b00166.

[29] L. Sang, A. Mudalige, A.K. Sigdel, A.J. Giordano, S.R. Marder, J.J. Berry, J.E. Pemberton, PM-IRRAS determination of molecular orientation of phosphonic acid self-assembled monolayers on indium zinc oxide, Langmuir 31 (2015) 5603-5613, https://doi.org/10.1021/acs.langmuir.5b00129.

[30] D. Volpati, P.H.B. Aoki, P. Alessio, F.J. Pavinatto, P.B. Miranda, C.J.L. Constantino, O.N. Oliveira, Vibrational spectroscopy for probing molecular-level interactions in organic films mimicking biointerfaces, Adv. Colloid Interface Sci. 207 (2014) 199-215, https://doi.org/10.1016/j.cis.2014.01.014.

[31] P.H.B. Aoki, L.F.C. Morato, F.J. Pavinatto, T.M. Nobre, C.J.L. Constantino, O.N. Oliveira, Molecular-level modifications induced by photo-oxidation of lipid monolayers interacting with erythrosin, Langmuir. 32 (2016) 3766-3773, https:// doi.org/10.1021/acs.langmuir.6b00693.

[32] G. Van Meer, I.P.M. Anton, G. Van Meer, A.I.P.M. De Kroon, Lipid map of the mammalian cell, J. Cell. Sci. 2011 (2011) 5-8, https://doi.org/10.1242/jcs. 071233.

[33] K. Marinic, D. Manoil, A. Filieri, J.C. Wataha, J. Schrenzel, N. Lange, S. Bouillaguet, Repeated exposures to blue light-activated eosin Y enhance inactivation of $\mathrm{E}$. faecalis biofilms, in vitro, Photodiagn. Photodyn. Ther. 12 (2015) 393-400, https:// doi.org/10.1016/j.pdpdt.2015.06.004.

[34] F. Freire, A.C.B.P. Costa, C.A. Pereira, M. Beltrame Junior, J.C. Junqueira, A.O.C. Jorge, Comparison of the effect of rose bengal- and eosin Y-mediated photodynamic inactivation on planktonic cells and biofilms of Candida albicans, Lasers Med. Sci. 29 (2014) 949-955, https://doi.org/10.1007/s10103-013-1435-x.

[35] S.T.G. Buck, F. Bettanin, E. Orestes, P. Homem-De-Mello, H. Imasato, R.B. Viana, J.R. Perussi, A.B.F. Da Silva, Photodynamic efficiency of Xanthene dyes and their phototoxicity against a carcinoma cell line: a computational and experimental study, J. Chem. 2017 (2017), https://doi.org/10.1155/2017/7365263.

[36] S. Sennato, F. Bordi, C. Cametti, C. Coluzza, A. Desideri, S. Rufini, Evidence of domain formation in cardiolipin-glycerophospholipid mixed monolayers. A thermodynamic and AFM Study, J. Phys. Chem. B 109 (2005) 15950-15957, https:// doi.org/10.1021/jp051893q.

[37] V.P.N. Geraldo, F.J. Pavinatto, T.M. Nobre, L. Caseli, O.N. Oliveira, Langmuir films containing ibuprofen and phospholipids, Chem. Phys. Lett. 559 (2013) 99-106, https://doi.org/10.1016/J.CPLETT.2012.12.064.

[38] F.J. Pavinatto, C.P. Pacholatti, E.A. Montanha, L. Caseli, H.S. Silva, P.B. Miranda T. Viitala, O.N. Oliveira, Cholesterol mediates chitosan activity on phospholipid monolayers and Langmuir - Blodgett films, Langmuir 25 (2009) 10051-10061, https://doi.org/10.1021/la901019p.

[39] Y. Ishitsuka, D.S. Pham, A.J. Waring, R.I. Lehrer, K.Y.C. Lee, Insertion selectivity of antimicrobial peptide protegrin-1 into lipid monolayers: effect of head group electrostatics and tail group packing, Biochim. Biophys. Acta - Biomembr. 1758 (2006) 1450-1460, https://doi.org/10.1016/j.bbamem.2006.08.001.

[40] Patricia Maria Nassar, Luís Eduardo Almeida, M. Tabak, Binding of Dipyridamole to
DPPG and DPPC Phospholipid Vesicles: Steady-State Fluorescence and Fluorescence Anisotropy Decay Studies, (1998), https://doi.org/10.1021/LA980449U.

[41] V.R. Batistela, D.S. Pellosi, F.D. De Souza, W.F. Da Costa, S.M. De Oliveira Santin, V.R. De Souza, W. Caetano, H.P.M. De Oliveira, I.S. Scarminio, N. Hioka, PKa determinations of xanthene derivates in aqueous solutions by multivariate analysis applied to UV-vis spectrophotometric data, Spectrochim. Acta - Part A Mol. Biomol. Spectrosc. 79 (2011) 889-897, https://doi.org/10.1016/j.saa.2011.03.027.

[42] J.L. Arrondo, F.M. Goñi, J.M. Macarulla, Infrared spectroscopy of phosphatidylcholines in aqueous suspension. A study of the phosphate group vibrations, Biochim. Biophys. Acta 794 (1984) 165-168 (Accessed 20 August 2017), http:// www.ncbi.nlm.nih.gov/pubmed/6547352.

[43] I. Zawisza, A. Lachenwitzer, V. Zamlynny, S.L. Horswell, J.D. Goddard, J. Lipkowski, Electrochemical and photon polarization modulation infrared reflec tion absorption spectroscopy study of the electric field driven transformations of a phospholipid bilayer supported at a gold electrode surface, Biophys. J. 85 (2003) 4055-4075, https://doi.org/10.1016/S0006-3495(03)74819-X.

[44] R. Vácha, P. Jurkiewicz, M. Petrov, M.L. Berkowitz, R.A. Böckmann, J. BaruchaKraszewska, M. Hof, P. Jungwirth, Mechanism of interaction of monovalent ions with phosphatidylcholine lipid membranes, J. Phys. Chem. B 114 (2010) 9504-9509, https://doi.org/10.1021/jp102389k.

[45] I.W. Levin, T.E. Thompson, Y. Barenholz, C. Huang, Two types of hydrocarbon chain interdigitation in sphingomyelin bilayers, Biochemistry. 24 (1985) 6282-6286, https://doi.org/10.1021/bi00343a036.

[46] L. Caseli, D. Sousa-Martins, M. Maia, A.A.S. Lima-Filho, E.B. Rodrigues, R. Belfort, An intraocular dye solution based on lutein and zeaxanthin in a surrogate internal limiting membrane model: a Langmuir monolayer study, Colloids Surf. B Biointerfaces 107 (2013) 124-129, https://doi.org/10.1016/j.colsurfb.2013.01. 076.

[47] J. Sarkar, J. Chowdhury, P. Pal, G.B. Talapatra, Ab initio, DFT vibrational calculations and SERRS study of Rhodamine 123 adsorbed on colloidal silver particles, Vib. Spectrosc. 41 (2006) 90-96, https://doi.org/10.1016/j.vibspec.2006.01.012.

[48] R. Mendelsohn, G. Mao, C.R. Flach, Infrared reflection-absorption spectroscopy: principles and applications to lipid-protein interaction in Langmuir films, Biochim Biophys. Acta - Biomembr. 1798 (2010) 788-800, https://doi.org/10.1016/j. bbamem.2009.11.024

[49] D.S. Pellosi, B.M. Estevão, J. Semensato, D. Severino, M.S. Baptista, M.J. Politi, N. Hioka, W. Caetano, Photophysical properties and interactions of xanthene dyes in aqueous micelles, J. Photochem. Photobiol. A Chem. 247 (2012) 8-15, https:// doi.org/10.1016/j.jphotochem.2012.07.009.

[50] J.F.D. Liljeblad, V. Bulone, E. Tyrode, M.W. Rutland, C.M. Johnson, Phospholipid monolayers probed by vibrational sum frequency spectroscopy: instability of unsaturated phospholipids, Biophys. J. 98 (2010) L50-L52, https://doi.org/10.1016/ j.bpj.2010.02.009.

[51] N.I. Krinsky, Singlet oxygen in biological systems, Trends Biochem. Sci. 2 (1977) 35-38, https://doi.org/10.1016/0968-0004(77)90253-5.

[52] P.H.B. Aoki, A.P. Schroder, C.J.L. Constantino, C.M. Marques, Bioadhesive giant vesicles for monitoring hydroperoxidation in lipid membranes, Soft Matter 11 (2015) 5995-5998, https://doi.org/10.1039/C5SM01019F.

[53] K.A. Riske, T.P. Sudbrack, N.L. Archilha, A.F. Uchoa, A.P. Schroder, C.M. Marques, M.S. Baptista, R. Itri, Giant vesicles under oxidative stress induced by a membraneanchored photosensitizer, Biophys. J. 97 (2009) 1362-1370, https://doi.org/10. 1016/j.bpj.2009.06.023.

[54] G.R. Buettner, The pecking order of free radicals and antioxidants: lipid peroxidation, $\alpha$-tocopherol, and ascorbate, Arch. Biochem. Biophys. 300 (1993) 535-543, https://doi.org/10.1006/abbi.1993.1074.

[55] G. van Ginkel, J.M. Muller, F. Siemsen, A.A. van' t Veld, L.J. Korstanje, M.A.M. van Zandvoort, M. Lou Wratten, A. Sevanian, Impact of oxidized lipids and antioxidants, such as vitamin $\mathrm{E}$ and lazaroids, on the structure and dynamics of unsaturated membranes, J. Chem. Soc. Faraday Trans. 88 (1992) 1901, https://doi.org/10. 1039/ft9928801901.

[56] J. Wong-Ekkabut, Z. Xu, W. Triampo, I.-M. Tang, D.P. Tieleman, L. Monticelli, Effect of lipid peroxidation on the properties of lipid bilayers: a molecular dynamic study, Biophys. J. 93 (2007) 4225-4236, https://doi.org/10.1529/biophysj.107. 112565.

[57] S. Sankhagowit, S.-H. Wu, R. Biswas, C.T. Riche, M.L. Povinelli, N. Malmstadt, The dynamics of giant unilamellar vesicle oxidation probed by morphological transitions, Biochim. Biophys. Acta - Biomembr. 1838 (2014) 2615-2624, https://doi org/10.1016/j.bbamem.2014.06.020.

[58] E. Schnitzer, I. Pinchuk, D. Lichtenberg, Peroxidation of liposomal lipids, Eur. Biophys. J. 36 (2007) 499-515, https://doi.org/10.1007/s00249-007-0146-2.

[59] G.O. Fruhwirth, A. Loidl, A. Hermetter, Oxidized phospholipids: from molecular properties to disease, Biochim. Biophys. Acta - Mol. Basis Dis. 1772 (2007) 718-736, https://doi.org/10.1016/j.bbadis.2007.04.009.

[60] J.W. Borst, N.V. Visser, O. Kouptsova, A.J.W. Visser, Oxidation of unsaturated phospholipids in membrane bilayer mixtures is accompanied by membrane fluidity changes, Biochim. Biophys. Acta - Mol. Cell Biol. Lipids. 1487 (2000) 61-73, https://doi.org/10.1016/S1388-1981(00)00084-6.

[61] R.P. Mason, M.F. Walter, P.E. Mason, Effect of oxidative stress on membrane structure: small-angle X-ray diffraction analysis, Free Radic. Biol. Med. 23 (1997) 419-425 (accessed December 5, 2017), http://www.ncbi.nlm.nih.gov/pubmed/ 9214578

[62] K. Kjaer, Some simple ideas on X-ray reflection and grazing-incidence diffraction from thin surfactant films, Phys. B Condens. Matter. 198 (1994) 100-109, https:// doi.org/10.1016/0921-4526(94)90137-6. 